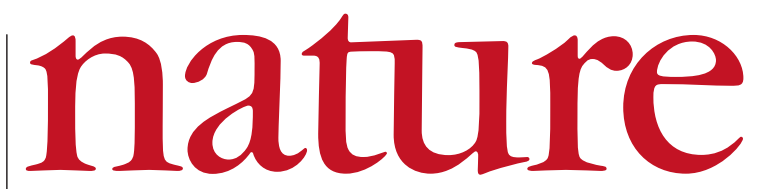

5 December 2002 Volume 420 Issue no 6915

\title{
Coping with a budget reversal
}

Last week's announcement by the German government of budget cuts in research are unwelcome but hardly surprising. The leaders of the research community need to focus on long-term restructuring to make the most of declining funds.

$\mathrm{T}$ he impression of decline is palpable in autumnal Germany. The inability of the Social Democrat-Green government, re-elected in September, to combat the crisis - a vicious circle of an ageing society, high unemployment, exploding costs of the social-security system, high taxes and weak consumer demand - dominates the newspaper headlines and political talk shows. Is the third-largest economy in the world really the weakest in Europe?

Widespread expressions of panic and the readiness, or glee, with which the media joined in the chorus of Cassandras are disturbing aspects of the crisis, which some commentators have compared to the decline of the Weimar Republic in the 1920s that helped fascism to gain power. But Germany's current slackness has little to do with a failure of the political system, and a lot to do with mass psychology and a lack of citizens' trust in the country's economic future.

Public spending is too high. Ironically, Germany, once a paragon of economic growth and stability, is likely to be sanctioned next year by the European Union (EU) for its failure to meet the Maastricht criteria for stability. Under these circumstances it is less unexpected than some science administrators would like to admit that the government has backed down from a pre-election promise to increase the budgets of Germany's main scientific organizations (see page 452).

But the decision comes at a precarious time for the German research system, which is in the midst of a difficult reform process. Two of its strongest pillars, the Deutsche Forschungsgemeinschaft (DFG) - the principal funding agency — and the elite research centres of the Max Planck Society (MPS), have been thoroughly evaluated in recent years. Both have since set up new initiatives aimed at fostering collaboration between researchers in and outside universities, and at increasing training opportunities for the best young scientists.

It would be a pity if these promising new schemes, such as the International Max Planck Research Schools and planned investment in high-profile research in eastern Germany, were to be halted.
Cutting the most recent, and least protected, achievements would be the path of least resistance. But there are better ways to respond to the current situation.

There is no shortage of evaluation of institutions and diagnosis of weaknesses, but the promised evaluation of the system as a whole has not been achieved. The autonomy of universities, in terms of employment and entrepreneurial freedom to pursue new opportunities in research and education, is under-developed. And while implementing change at universities is a challenge, the main pillars of non-university research - the MPS, the Hermann von Helmholtz Association of National Research Centres, the Fraunhofer Society for applied research, and the Leibniz Association - remain too isolated. These opportunities would, in the long term, allow Germany's research base to save far more than the E100 million (US\$100 million) or so that the science organizations need to save next year.

European statistics published last week show that in the 1990s Germany managed to maintain and strengthen its scientific productivity, while creating an entire research base in the east. But the MPS, the DFG and other German research organizations must strengthen their mechanisms of quality control to be able to allocate resources even more effectively.

The age structure of the MPS provides an opportunity for the society to smoothly renew itself. One-third of its scientific directors will retire in the next few years - a period it must use to carefully rethink its priorities. A smaller and healthier MPS is preferable to an over-staffed apparatus with little money left for investment.

In the long term, the image abroad of Germany will not depend on whether or not its research receives 3\% more in 2003 . What will make a difference, however, is whether or not the country manages to tackle the structural problems that it has allowed to accumulate over the past quarter-century. If Germany's universities and research organizations lead the way, so much the better.

\section{Promoting animal research}

\section{Researchers need to be more active in explaining the value and necessity of their work.}

$\mathrm{T}$ he odds are that there will ultimately be a favourable outcome to a planning inquiry currently under way in Cambridge, UK, examining the case for a new centre for primate neuroscience at the university. It is being held under the auspices of the local authority, which previously decided against the centre for the unusual reason that the probable public protests would be too problematic. The outcome will be referred (probably early next year) to the British deputy prime minister, John Prescott, for a final decision, and the government has rightly declared the centre to be a national 'need' — thus, incidentally, justifying construction on a site of protected 'green field' status.

The arguments being deployed in the inquiry are not about science. However, opponents are disputing the 'need' on the quasi-scientific and fallacious grounds that animal research is both misleading and unnecessary, given available alternatives.

What is striking about the debates is the near-invisibility of the scientific community, apart from the stalwart but predictable Research Defence Society. This absence of active researchers does nothing but help the opponents of essential research that has in the past attracted broad public acceptance. Certainly, some animal researchers have been treated viciously in other contexts, but objectors here have restricted themselves to presenting the arguments.

The evidence of opinion polls and the lack of public hostility to some people who have recently supported animal research suggests that a well-planned campaign of information and public representation can keep the worst excesses at bay. Relying on individual researchers to stand prominently in isolation is a recipe for scientific and democratic failure. It is feasible for scientists to band together to campaign on a single issue. Whatever happens at Cambridge, collective public representation in Britain and elsewhere of the animal researchers' case needs to be developed in a professional manner. 